\title{
A new basal sphenacodontid synapsid from the Late Carboniferous of the Saar-Nahe Basin, Germany
}

Jörg Fröbisch, Rainer R. Schoch, Johannes Müller, Thomas Schindler, and Dieter Schweiss

Acta Palaeontologica Polonica 56 (1), 2011: 113-120 doi: http://dx.doi.org/10.4202/app.2010.0039

A new basal sphenacodontid synapsid, represented by an anterior portion of a mandible, demonstrates for the first time the presence of amniotes in the largest European Permo-Carboniferous basin, the Saar-Nahe Basin. The new taxon, Cryptovenator hirschberger i gen. et sp. nov., is autapomorphic in the extreme shortness and robustness of the lower jaw, with moderate heterodonty, including the absence of a greatly reduced first tooth and only a slight caniniform development of the second and third teeth. Cryptovenator shares with Dimetrodon, Sphenacodon, and Ctenospondylus, but notably not with Secodontosaurus, enlarged canines and a characteristic teardrop outline of the marginal teeth in lateral view, possession of a deep symphyseal region, and a strongly concave dorsal margin of the dentary. The new find shows that sphenacodontids were present in the Saar-Nahe Basin by the latest Carboniferous, predating the record of sphenacodontid tracks from slightly younger sediments in this region.

Key words: Synapsida, Sphenacodontidae, Carboniferous, Saar-Nahe Basin, Germany.

Jörg Fröbisch [jfrobisch@fieldmuseum.org], Department of Geology,

The Field Museum, 1400 South Lake Shore Drive, Chicago, Illinois

60605, USA and and [joerg.froebisch@mfn-berlin.de],

Museum für Naturkunde Leibniz-Institut für Evolutions- und

Biodiversitätsforschung an der Humboldt-Universität zu

Berlin, Invalidenstr. 43, D-10115 Berlin, Germany; Rainer R.

Schoch [schoch.smns@naturkundemuseum-bw.de], Staatliches

Museum für Naturkunde, Rosenstein 1, D-70191 Stuttgart, Germany;

Johannes Müller [johannes.mueller@mfn-berlin.de], Museum für

Naturkunde - Leibniz-Institut für Evolutions- und Biodiversitätsforschung

an der Humboldt-Universität zu Berlin, Invalidenstr. 43, D-10115 Berlin,

Germany; Thomas Schindler [psg.t.schindler@t-online.de], Büro für

Paläontologie, Stratigraphie und Geotopschutz, Am Wald 11, D-55595

Spabrücken, Germany; Dieter Schweiss [dj.schweiss@t-online.de], Geoskop Urweltmuseum, Burg

Lichtenberg, D-66871 Thallichtenberg, Germany. 
This is an open-access article distributed under the terms of the Creative Commons

Attribution License (for details please see creativecommons.org), which permits unrestricted use, distribution, and reproduction in any medium, provided the original author and source are credited.

Faris: Full text $(367.3 \mathrm{kB})$ ।

Far Supplementary file $(221.6 \mathrm{kB})$ 